\title{
Social Life Cycle Assessment of a Proton Exchange Membrane Fuel Cell stack
}

\author{
Eleonora Bargiacchi ${ }^{1, *}$, Felipe Campos-Carriedo ${ }^{1}$, Diego Iribarren $^{1}$ and Javier Dufour ${ }^{1,2}$ \\ ${ }^{1}$ IMDEA Energy, Systems Analysis Unit, 28935, Móstoles, Spain \\ ${ }^{2}$ Rey Juan Carlos University, Chemical and Environmental Engineering Group, 28933, Móstoles, Spain
}

\begin{abstract}
Hydrogen systems are gaining importance in view of a progressive decarbonisation of societies, and becoming more and more cost-competitive alternatives in many sectors (e.g., mobility). However, the sustainability of these technologies must be carefully assessed following a holistic approach which embraces not only environmental but also social aspects. Social Life Cycle Assessment (S-LCA) is an insightful methodology to evaluate potential social impacts of products along their life cycle. In the frame of the project eGHOST, social risks of a proton exchange membrane fuel cell (PEMFC) stack were assessed through an S-LCA. The functional unit was defined as one $48 \mathrm{~kW}$ stack (balance of plant excluded), targeted for mobility applications. The supply chain was defined assuming Spain as the manufacturing country and involving from the material/energy production plants to the stack manufacturing. Beyond conventional life cycle inventory data, trade information and additional inventory data were retrieved from the UN Comtrade and PSILCA databases, respectively. Besides, working hours for the manufacturing plants of the stack and its subcomponents were calculated based on literature data. Social life cycle inventories were modelled and evaluated using openLCA and the PSILCA method. Two stakeholder categories, workers and society, were considered through the following social indicators: child labour, contribution to economic development, fair salary, forced labour, gender wage gap, and health expenditure. The choice of these indicators is in line with the eGHOST project purpose. Despite the relatively small amount contained in the product, platinum clearly arose as the main social hotspot under each of the selected indicators. At the level of component plants, the manufacturing of bipolar and end plates was also found to be relevant under some indicators. On the other hand, electricity consumption generally accounted for a minor contribution. Overall, in order to avoid burden shifting from environmental to social issues, a careful design of technologies is needed.
\end{abstract}

\section{Introduction}

Hydrogen technologies are expected to play a key role in achieving the decarbonisation objectives in the European energy transition (1). This will imply enormous investments in the Fuel Cells and Hydrogen (FCH) sector and a sharp increase in the number of hydrogen production and use devices. Such a ramp-up of the sector will provide beneficial environmental and societal impacts, in particular related to pollution reduction and economic development (1). On the other hand, the steep development and market penetration of $\mathrm{FCH}$ systems could create environmental or social issues along their whole supply chain, for instance related to the presence of critical raw materials. Hence, a careful analysis is necessary to avoid burden shifting. Regarding social issues, Social Life Cycle Assessment (S-LCA) has proved to be an effective and increasingly applied methodology to assess the potential social impacts of product systems along their supply chain (2). Updated guidelines have been developed by the United Nations
Environment Programme (UNEP) (3). However, few studies have addressed the social life-cycle impacts of FCH systems $(4,5)$, and therefore further effort is needed for a complete assessment of $\mathrm{FCH}$ products through a comprehensive approach including social, economic and environmental dimensions (Life Cycle Sustainability Assessment, LCSA). This paper aims at assessing the social life-cycle impacts associated with the manufacturing of a $48 \mathrm{~kW}$ Proton Exchange Membrane Fuel Cell (PEMFC) stack, in the framework of the EUfunded project eGHOST (6). Within this project, this SLCA study will complement the corresponding environmental Life Cycle Assessment (LCA) and Life Cycle Costing (LCC) to build a robust LCSA that drives the eco-(re)design of the PEMFC stack.

\footnotetext{
* Corresponding author: eleonora.bargiacchi@imdea.org
} 


\section{Methodology}

\subsection{Definition of the case study}

The reference product is a $48 \mathrm{~kW}$ PEMFC stack, intended for mobility applications. The stack specifications and detailed bill of materials was provided by the manufacturing company SYMBIO. In particular, the stack is designed for subsequent use as a range extender fuel cell for electric vehicles (EV) or as a dual/full-power system for light fuel cell electric vehicles (FCEV). The core of each cell of the stack, where the electrochemical reactions take place, is constituted by the Membrane Electron Assembly (MEA), composed of a Proton Exchange Membrane (PEM), two catalyst layers (made of platinum nanoparticles on a carbon support) and two Gas Diffusion layers (GDL), as shown in Figure 1a.

Gas flows are guided to and removed from the reaction sites throughout the bipolar plates, which separate the cells from one another and provide mechanical support. The power unit is obtained by stacking the unitary entities together by using conventional connectors (screws, clamps, bolts, springs...) and gaskets to ensure tightness (Figure 1b). Finally, the current collector conducts the electricity produced by the stack out of the system.

\subsection{Goal and scope}

The goal of the work is to carry out a detailed S-LCA on the PEMFC stack introduced in Section 2.1. The functional unit (FU) is one PEMFC stack (Balance of Plant - BoP - excluded) The system boundaries are set according to the supply chain definition as explained below.

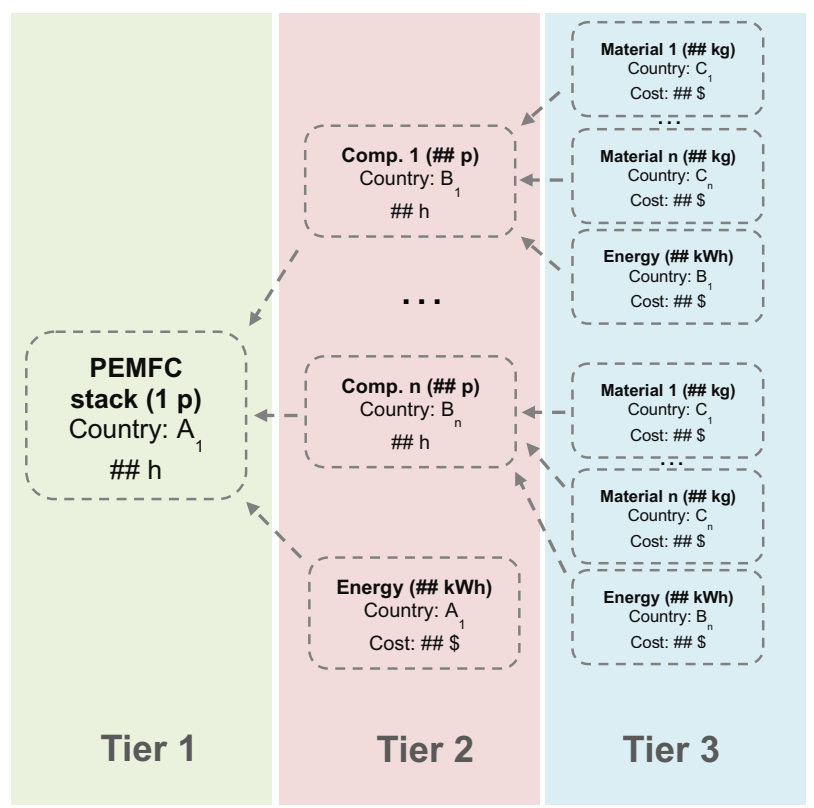

Figure 2. Inventory segmentation for S-LCA
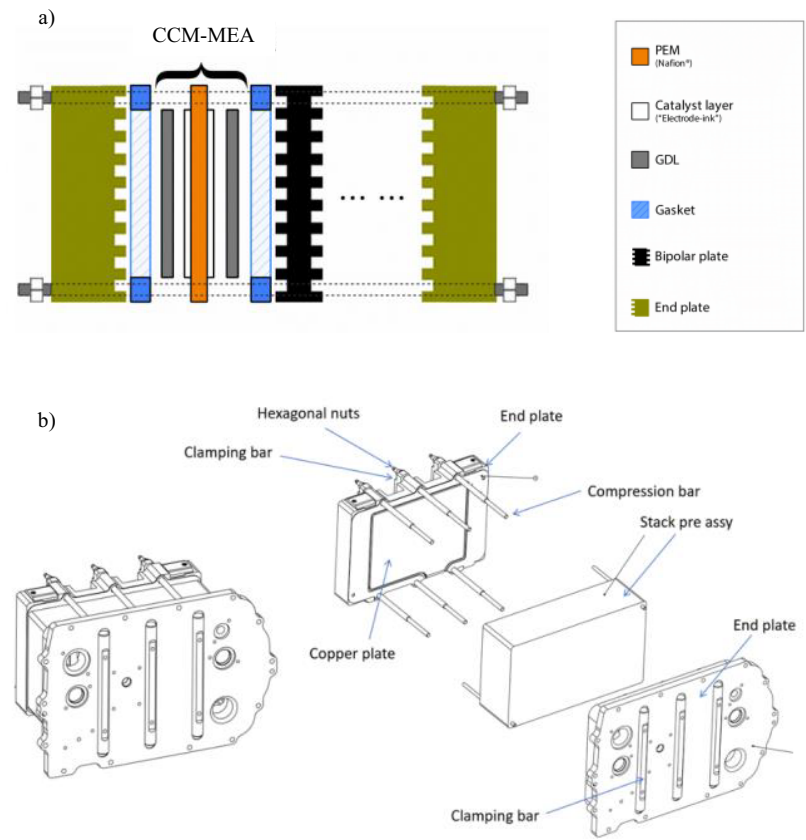

Figure 1. a) Membrane Electrode Assembly (MEA) main components. b) PEMFC stack assembly final step manufacturing. Adapted from (6)
Along the supply chain of the system under evaluation, three tiers are considered, as shown in Figure 2. Tier 1 refers to the stack manufacturing plant; tier 2 involves the plants related to the production of the stack components and the energy flows required by tier 1 ; and tier 3 contains the plants where the materials and energy flows required by tier 2 are produced. Spain is set as the manufacturing country in tier 1 .

The protocol followed to identify the countries involved in the supply chain of the PEMFC stack is based on (7). Setting Spain (final product manufacturer) as the declarant entity, global trade data for each stack component are acquired from the UN Comtrade database (8). A component is found to be also manufactured in Spain if its monetary export-import balance is positive. On the other hand, if the balance is negative, the main exporter is identified. In the end, one manufacturing country is assigned to each of the product components.

When the previous step is completed, a similar procedure is applied to define the origin of tier 3 materials. Each component manufacturing country is set as declarant for every material flow within that component and typified analogously by its trade balance result. However, when identifying relevant exporters, a mix of the ones accounting for more than $50 \%$ of global exports to the 
declarant country could be found (not necessarily focusing only on the top one as in tier 2).

Tier 2 energy flows are located in Spain. Tier 3 energy flows are located in each of the component manufacturing countries

\subsection{Data acquisition and characterisation}

The main source of data for the S-LCA is constituted by the LCA and LCC inventories together with the use of the PSILCA (Product Social Impact Life Cycle Assessment) database (9), which is used as both a database and an impact assessment method. The activity variable that allows impacts calculation is working hours, which are retrieved from literature sources for each manufacturing process at the stack component level. The assessment is performed using the openLCA software. The choice of the social indicators to be studied is based on the specific goal of the eGHOST project (i.e. the development of ecodesign criteria for $\mathrm{FCH}$ products), literature results from previous life-cycle studies of FCH systems (10-12) and the Sustainable Development Goals. Child labour, forced labour and fair salary are selected within the stakeholder category "workers", and health expenditure and contribution to economic development are considered within the category "society".

\section{Results and discussion}

\subsection{Social life cycle inventory}

The resultant social life cycle inventory of the $48 \mathrm{~kW}$ PEMFC stack, is presented in Figure 3. All values correspond to the functional unit of one stack and monetary flows are expressed in 2015 American Dollars.
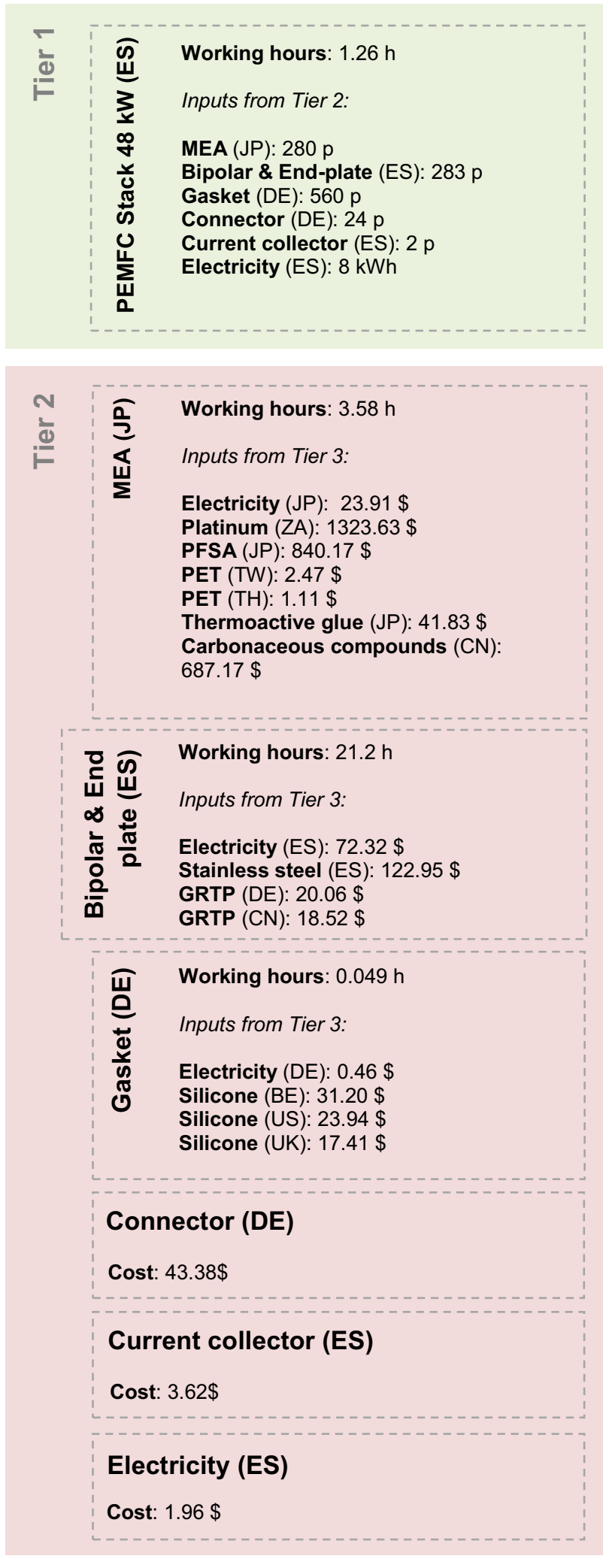

Figure 3. Social life cycle inventory of a 48 kW PEMFC Stack 


\subsection{Social life cycle impact assessment}

The social life cycle profile and the process contribution to the selected impact categories are shown in Figure 4. Despite its low mass fraction $(<0.1 \%$ of the total mass of the stack), platinum production in South Africa arises as the main social hotspot for every impact category apart from "contribution to economic development". This is mainly linked to the high specific cost of platinum and the high sector-specific risk level in the relevant manufacturing country (South Africa). The manufacturing of carbonaceous compounds in China is the main contributor to economic development. Among the stack components, bipolar and end plates manufacturing shows a relevant contribution in 5 out of 6 indicators since these components make up $74 \%$ of the total mass of the stack. Overall, manufacturing processes at the level of materials are found to present higher social risks than manufacturing processes at the level of components, while the social risks associated with energy production plants are negligible due to the involvement of low-risk countries.

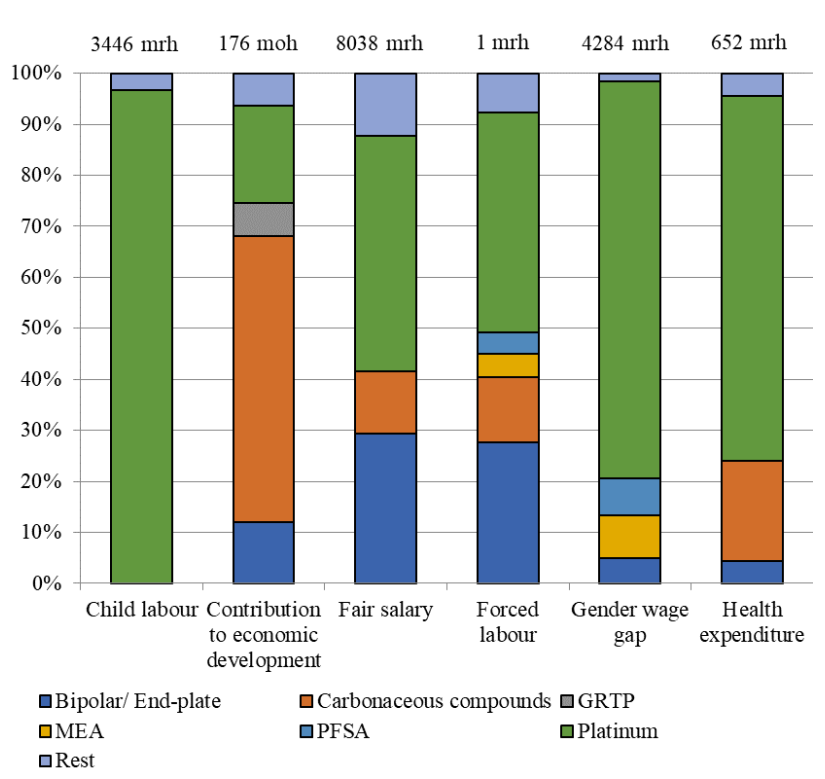

Figure 4. Impact assessment results and process contribution of the reference product

\section{Conclusions}

In this work the S-LCA of a $48 \mathrm{~kW}$ PEMFC stack was performed. Even though platinum means $<0.1 \%$ of the total stack weight, its production arises as the key social hotspot over the assessed social indicators due to its high cost and country-specific social risks. A careful ecodesign aiming at reducing the catalyst loading is therefore recommended, as well as promoting its recovery in the end-of-life phase.

\section{Acknowledgments}

This work was carried out in the context of the project eGHOST. This project has received funding from the Fuel Cells and Hydrogen 2 Joint Undertaking under Grant Agreement No 101007166. This Joint Undertaking receives support from the European Union's Horizon 2020 Research and Innovation programme, Hydrogen Europe and Hydrogen Europe Research. The authors acknowledge CEA, SYMBIO and University of Ljubljana for valuable scientific exchange.

\section{Nomenclature}

\begin{tabular}{|c|c|}
\hline $\mathrm{BE}$ & Belgium \\
\hline $\mathrm{BoP}$ & Balance of Plant \\
\hline $\mathrm{CCM}$ & Catalyst Coated Membrane \\
\hline $\mathrm{CN}$ & China \\
\hline $\mathrm{DE}$ & Germany \\
\hline EoL & End of Life \\
\hline ES & Spain \\
\hline EU & European Union \\
\hline EV & Electric Vehicle \\
\hline FCEV & Fuel Cell Electric Vehicle \\
\hline $\mathrm{FCH}$ & Fuel Cells and Hydrogen \\
\hline FU & Functional Unit \\
\hline GDL & Gas Diffusion Layer \\
\hline GRTP & Glass Reinforced Thermoplastic \\
\hline JP & Japan \\
\hline LCA & Life Cycle Assessment \\
\hline $\mathrm{LCC}$ & Life Cycle Costing \\
\hline LCSA & Life Cycle Sustainability Assessment \\
\hline MEA & Membrane Electrode Assembly \\
\hline moh & medium opportunity hours \\
\hline MPL & Microporous Layer \\
\hline $\mathrm{mrh}$ & medium risk hours \\
\hline PEMFC & Proton Exchange Membrane Fuel Cell \\
\hline PET & Polyethylene Terephthalate \\
\hline PFSA & Perfluorosulfonic acid \\
\hline S-LCA & Social Life Cycle Assessment \\
\hline $\mathrm{TH}$ & Thailand \\
\hline TW & Taiwan \\
\hline UK & United Kingdom \\
\hline UN & United Nations \\
\hline US & United States of America \\
\hline ZA & South Africa \\
\hline
\end{tabular}




\section{References}

1. Fuel Cells and Hydrogen Joint Undertaking. Hydrogen Roadmap Europe. 2019. Available from: https://fch.europa.eu

2. Ramos Huarachi DA, Piekarski CM, Puglieri FN, de Francisco AC. Past and future of Social Life Cycle Assessment: Historical evolution and research trends. J Clean Prod. 2020;264:121506.

3. United Nations Environment Programme. Guidelines for Social Life Cycle Assessment of Products and Organizations 2020. Benoît Norris C, Traverso M, Neugebauer S, Ekener E, Schaubroeck T, Russo Garrido S, Berger $M$, Valdivia $S$, Lehmann $A$, Finkbeiner $M$, Arcese G (eds.). UNEP; 2020.

4. Schlör H, Koj J, Zapp P, Schreiber A, Hake JF. The Social Footprint of Hydrogen Production - A Social Life Cycle Assessment (S-LCA) of Alkaline Water Electrolysis. Energy Procedia 2017;105:3038-44.

5. Werker J, Wulf C, Zapp P. Working conditions in hydrogen production: A social life cycle assessment. J Ind Ecol. 2019;23(5):1052-61.

6. eGHOST. Establishing Eco-design Guidelines for Hydrogen Systems and Technologies.
2021. Available from: https://eghost.eu

7. Martín-Gamboa M, Dias AC, Arroja L, Iribarren D. A protocol for the definition of supply chains in product social life cycle assessment: application to bioelectricity. Sustain Energy Fuels. 2020;4:5533-42.

8. United Nations. UN Comtrade database. [cited 2021 Sep 10]. Available from: https://comtrade.un.org/

9. Maister K, Di Noi C, Ciroth A, Srocka M. PSILCA database v.3 documentation. Green Delta; 2020.

10. Valente A, Iribarren D, Dufour J. Comparative life cycle sustainability assessment of renewable and conventional hydrogen. Sci Total Environ. 2021;756:144132.

11. Valente A, Iribarren D, Dufour J. Life cycle sustainability assessment of hydrogen from biomass gasification: A comparison with conventional hydrogen. Int J Hydrogen Energy. 2019;44(38):21193-203.

12. Martín-Gamboa M, Quinteiro P, Dias AC, Iribarren D. Comparative social life cycle assessment of two biomass-to-electricity systems. Int J Environ Res Public Health. 2021;18(9): 4918. 